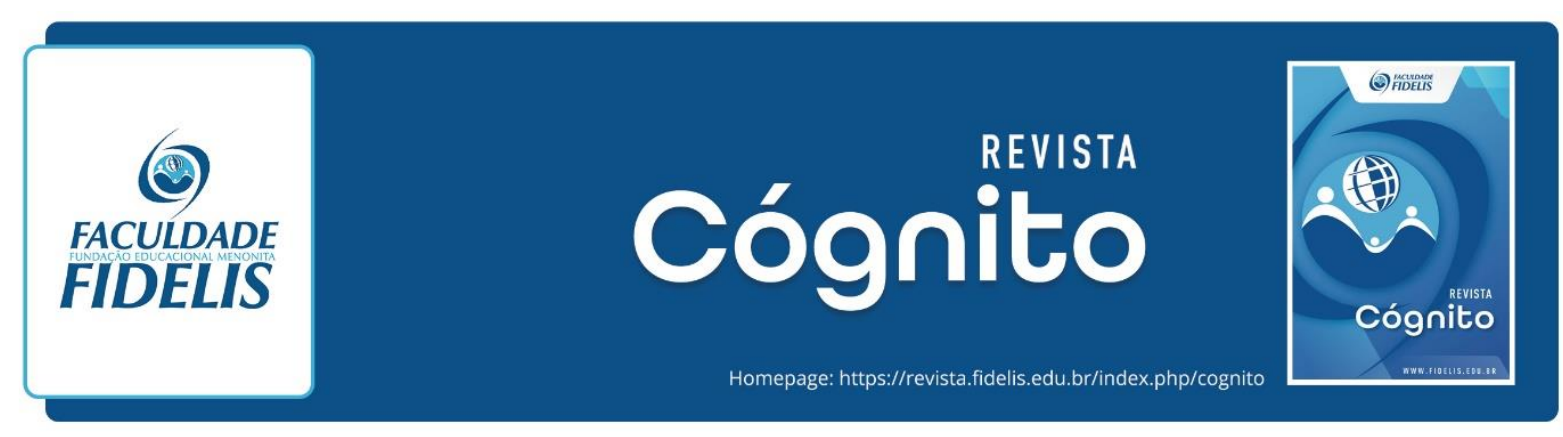

\title{
CONCEITOS, TEORIAS E CONTEMPORANEIDADE NA FORMAÇÃO DE PROFESSORES E DE PROFESSORAS
}

\section{Concepts, theories and contemporaneity in teacher education}

\author{
Caio Corrêa Derossi ${ }^{1}$ \\ Karen Laíssa Marcílio Ferreira ${ }^{2}$ \\ Ana Claudia Lopes Chequer Saraiva ${ }^{3}$
}

\begin{abstract}
RESUMO
O presente texto apresenta um balanço bibliográfico acerca dos principais conceitos e teorias do campo de estudo da formação de professores, bem como a relevância contemporânea de tais debates para a sociedade. Assim, em um primeiro momento, discutirá a categoria teórica de formação, associada à docência. E, em seguida, o foco será a formação inicial de professores, marcando as concepções, as políticas públicas e as implicações com as práticas educativas. Como considerações finais e tônica que percorre o texto, a formação é entendida como momento que acontece por toda a vida, mas que em sua fase inicial, é importante para a inserção na docência, bem como para assumir o compromisso social de transformação da educação e da profissão.
\end{abstract}

Palavras-chave: Formação de professores. Formação Inicial. Desenvolvimento Profissional da Docência.

\section{ABSTRACT}

This text presents a bibliographic balance about the main concepts and theories of the field of study of teacher education, as well as the contemporary relevance of such debates for society. Thus, at first, it will discuss the theoretical category of training, associated with teaching. And then, the focus will be on the initial training of teachers, marking the conceptions, public policies and implications with educational practices. As final considerations and tonic that runs through the text, training is understood as a moment that happens throughout life, but in its

\footnotetext{
${ }^{1}$ Mestrando em Educação pela UFV.derossi.caio@gmail.com

${ }^{2}$ Discente em Educação Infantil na UFV.

${ }^{3}$ Doutora em Educação pela UFMG. Docente na Universidade Federal de Viçosa
} 
initial phase, it is important for insertion in teaching, as well as for assuming the social commitment to transform education and profession.

Keywords: Teacher training; Initial formation; Professional Development of Teaching.

\section{PALAVRAS INICIAIS}

O homem, enquanto ser humano, tem centralidade para se refletir sobre a formação, pois além de ser sujeito do processo formativo, é produtor e intérprete de conhecimentos e saberes, que impactam nas formas como se vive, se comunica, em uma esfera individual como também coletiva. Nas palavras de Vieira Pinto (1969, p. 281),

\footnotetext{
O homem, por definição, é o ser que se propõe por finalidade a criação da realidade em que deseja existir. Conjuntamente com a transformação do mundo, transforma-se a sua própria realidade, de tal sorte que novos fins vão sendo propostos pela consciência, num processo sem término. O homem se define como o ser capaz de projetar o seu ser, de conceber por finalidade o que quer ser. É, pois, o existente que se faz a si próprio. (VIEIRA PINTO, 1969, p. 281).
}

Assim, a partir de Vieira Pinto (1969) pode-se pensar que o ser humano é um sujeito agente, criativo, com poder transformador e de criação de objetos concretos, inteiros, que mesmo em diferentes contextos ou se tratando de atividades consideradas como simples ou cotidianas, mobiliza um conjunto de saberes e fazeres próprios. Portanto, o processo de transformar a realidade é um contínuo para os seres humanos encaminhando a produção de saberes próprios, que impactam sua constituição enquanto sujeito e suas relações com o mundo.

Nesse sentido, assume-se aqui uma postura epistemológica para análise que concebe o ser humano enquanto um sujeito histórico, produtor e produto de um contexto social, produtor de saberes e de conhecimentos, frente as relações que constrói com o mundo, com os sujeitos e as demais situações sociais.

Refletindo sobre o termo formação, em sua gênese, retoma as origens latinas, do sintagma formatio, referindo-se a ação de formar, dar forma, constituir um objeto ou um grupo de pessoas a partir de determinado padrão, modelo ou composição. Pensar em formação, implica em revisitarmos nossas histórias e nossas trajetórias escolares, educativas e perpassa também, uma noção de evolução, de transformações graduais, inserida em aspectos de tempo, de duração e de espaço, de forma ascendente, na maior parte das vezes. Neste percurso, trazemos à tona, desejos, vontades, quereres, realidades externas, interpretações subjetivas e a construção de um caminho visando onde se quis/quer chegar. 
A formação, seja ela realizada em caráter formal ou não-formal, mobilizadas por aparatos legais e/ou pelo desejo dos sujeitos, são fenômenos globais e sociais, por se apresentarem em todas as sociedades, cada qual com idiossincrasias, e por apresentar uma prática educativa, entendida à luz de Libâneo (1994, p. 16)

[...] como um fenômeno social e universal, sendo uma atividade humana necessária à existência e funcionamento de todas as sociedades. Cada sociedade precisa cuidar da formação dos indivíduos, auxiliar no desenvolvimento de suas capacidades físicas e espirituais, prepará-los para a participação ativa e transformadora nas várias instâncias da vida social. Não há sociedade sem prática educativa. A prática educativa não é apenas uma exigência da vida em sociedade, mas também o processo de prover os indivíduos dos conhecimentos e experiências culturais que os tornam aptos a atuar no meio social e a transformá-lo em função de necessidades econômicas, sociais, políticas da coletividade. (LIBÂNEO, 1994, p. 16).

Tendo em vista o exposto, a formação e todos os processos envolvidos são de caráter contínuo, evidenciando uma condição eterna de inacabamento do sujeito, de aprendizagem constante, a qual a educação, enquanto uma produção por/para si, contribui para, segundo Charlot (2000, p. 60)

\begin{abstract}
Aprender para se construir, segundo um triplo processo de hominização (tornar-se homem) de singularização (tornar-se um exemplar único de homem), de socialização (tornar-se membro de uma comunidade, da qual se partilham os valores e em que se ocupa um lugar). Aprender para viver com outros homens com os quais se partilha o mundo. (CHARLOT, 2000, p. 60).
\end{abstract}

Todo o processo formativo é imiscuído e pertencente de fatores e orientações sociais, familiares, políticas e econômicas, que representam períodos específicos e contextos de esferas macro e micro, que mediam a formação. Assim, o conceito de formação foi apropriado, entre outras áreas, pela educação, interligando-se principalmente aos professores ${ }^{4}$ e colocado assim, à ribalta das discussões, por aparecer, com a sua característica lata, associada a diferentes análises, perspectivas epistemológicas e reflexões. Portanto, partindo da análise e compreensão do conceito de formação, tecer-se-ão algumas considerações e premissas sobre os processos formativos na constituição da profissão docente e seus demais envolvimentos.

\footnotetext{
${ }^{4}$ Com o objetivo de tornar a leitura mais dinâmica e ciente da quantidade de vezes que a palavra é citada durante o texto, pede-se que toda vez que aparecer os sintagmas professor e/ou professores, que se interprete como professor(es) e professora(s).
} 
García (1999) apresenta alguns sentidos do conceito de formação e destaca que, como em outros termos do campo educacional, ele pode ser polissêmico e implicado com diferentes contextos. Dentre as significações atribuídas a formação, García ressalta que, de forma geral, existe uma associação entre a categoria e o conceito de desenvolvimento profissional. Assim, o autor aponta o entendimento de Zabalza (1999) que propõe que a formação é fruto do desenvolvimento e dos demais processos que encaminham para o cumprimento de objetivos pessoais. García também retoma a contribuição de González Soto (1989) que entende que o processo formativo é inserido em um contexto sócio histórico e que retrata a busca do sujeito por suas identidades. Por fim, García aponta os contributos de Ferry (1991) no sentido de entender que a formação ocorre por meios que são oferecidos aos indivíduos ou fruto da procura individual, representando um trabalho imaginado e livre sobre si, frente ao que se deseja e procura.

A partir dos autores e dos destaques elencados por García (1999), entende-se a relação entre a formação e o desenvolvimento profissional, em função do segundo estar implicado com ações educativas sistematizadas que visam coadunar os conhecimentos e os saberes dos conteúdos, dos professores, dos alunos e das comunidades, bem como propor um desenvolvimento pessoal, para além do ensino formal, refletindo as aprendizagens ao longo da vida. Portanto, o desenvolvimento profissional é comumente relacionado também a aspectos e valores que retomam a vida do sujeito, uma vez que esses componentes impactam os projetos formativos, oferecendo um tom humanizado a eles.

Assim, para García (1999) entende que os elementos pessoais envolvidos na formação, não se associam simplesmente a um desenvolvimento autônomo ou a um treino, mas sim, é uma forma que os próprios sujeitos têm para assumir um protagonismo no processo formativo, uma vez que, eles retomam a própria história escolar, aos seus imaginários, representações e conhecimentos que foram e não apropriados. Logo, fica evidenciado que o sujeito precisa estar imbricado, mobilizado com os demais sujeitos e com os espaços formativos.

García (1999) apontou ainda que, em função do termo formação ser amplo e intercruzado por outros conceitos, alguns autores imaginaram a necessidade de propor uma teoria da formação, a exemplo de outras da educação e da aprendizagem. Fullat (1994) entende como positiva uma teoria da formação, já que ela representaria a soma de esforços para o entendimento de premissas antropológicas sobre o ser humano e sua constituição, através de métodos e sistemática organizados. Em suas palavras, "formação provém de forma e assinala a 
ação de dar forma, de configurar, [...] com o passar do tempo procurou-se enriquecer o significado de formação em distintas direções conceituais” (FULLAT, 1994, p. 36).

Nesse sentido, García (1999) apresenta com base em Menze (1980), quatro teorias da formação, que os demais autores supracitados também já haviam realizados referências. Assim, em primeiro lugar, García destaca a Teoria da Formação Formal, que enfoca os aspectos cognitivos do conhecimento, suas formas de estruturação, suas apropriações, com vistas a refletir sobre como os indivíduos aprendem. Nessa perspectiva então, a formação é direcionada para os desenvolvimentos psíquico e intelectual do sujeito. Em um segundo momento, García destaca a Teoria da Formação Categorial, que se apresenta de forma dialética, a partir de três fases de reflexão, pensando nos campos intuitivo e prático do objeto observado, depois o afastamento do campo de observação e por último a análise e a compreensão do que fora estudado. Tal Teoria aposta que as etapas ofereceriam uma visão mais consistente do fenômeno, bem como contribuiriam com o desenvolvimento cognitivo do sujeito, ao passo que durante o processo de investigação, hipóteses, perguntas e questões são postas. A terceira vertente, denominada de Teoria Dialogística da Formação, pondera que para além de um saber próprio de um campo disciplinar, a formação deve permitir que o sujeito interligue a realidade vivida por ele com os conhecimentos formais, visando também sua auto realização, a liberdade. Já a Teoria da Formação Técnica, quarta e última retratada por García, que em conjunto aos pressupostos do humanismo e pensando em atender anseios objetivos da sociedade, propõe que é a partir da formação técnica o sujeito pode aprender de forma contínua.

Cabe ressaltar que, as teorias e definições elencadas por García (1999) não se findam nelas mesmas, uma vez que as discussões acerca do conceito de formação percorrem por diferentes campos conceituais, se mantendo ainda em aberto para novas análises e compreensões. Entretanto, como destaca Perissé (2008) quando se observa o panorama conceitual da categoria e a busca entender de modo reflexivo, mais itinerários são abertos para os debates acerca das práticas cotidianas, dos interlocutores e com a comunidade escolar.

Com a série de mudanças sobre o conceito de formação e suas distintas teorias com limites e possibilidades, é percebido que, a partir de uma lógica social contemporânea, pautada na informação, nas tecnologias digitais de comunicação, na mundialização de parâmetros político-econômicos, a formação é cada vez mais pautada e cobrada pelos/aos sujeitos em meio as descontinuidades globais. Nesse sentido, Debesse (1982) apresenta três tipos de formação, a saber: a auto formação, organizada independentemente pelo sujeito; a heteroformação, que foca na organização de conhecimentos externos ao sujeito e a interformação, que entende o processo 
formativo através das trocas de conhecimentos entre os envolvidos. Assim, para além de refletir sobre modelos de formação docente, García (1999) retoma ao último tipo de formação citado, indicando que esse pode ser uma perspectiva fortuita, pois as trocas entre os professores podem evidenciar seus contextos de atuação e suscitar caminhos que podem ser percorridos em suas práticas.

Assim, García (1999) ressalta que o processo de interformação de professores, pode ocorrer em sua fase inicial ou continuada, privilegiando as atividades em grupos, as trocas interpessoais, que oferecem o tom do desenvolvimento profissional, que é o coletivo, o social. O processo formativo parte de pontos de toque em comum entre as histórias e as práticas educativas dos sujeitos associados as cores locais do trabalho e das realidades construídas por cada professor.

Levando em consideração os estudos de Debesse (1982) e de García (1999), os tipos de formação não são hermeticamente opostos ou antagônicos, uma vez que, a interformação e a auto formação podem ser paralelas. A última citada, tendo como característica principal a demanda interna e própria de mudança do professor, pode ser sim, impactada pelas trocas de experiências, conversas com demais professores, já que o sujeito é localizado a partir de aspectos temporais, locais e relacionais, já que são esses, entre outros aspectos que constituem os sujeitos e suas identidades. Pode-se considerar inclusive, que as demandas externas da heteroformação também geram impactos nas dimensões pessoal e de troca entre os sujeitos. Nesse sentido, Nóvoa (1992) destaca que a correlação entre os aspectos da auto e da inter formações, podem corroborar para a formação de profissionais críticos e reflexivos. Por isso, o autor faz a defesa que os professores se utilizem da auto formação como uma das principais precursoras do processo formativo e do desenvolvimento profissional da docência.

Como já fora citado, por se tratar de um conceito dinâmico, histórico e holístico, a formação de professores pode e foi encarada e concebida de distintas formas, a depender do tempo e da teoria. Para além das elucubrações teóricas, os sujeitos que trabalham como docentes e a assumem como profissão, precisam pensar em uma formação contínua que vise o desenvolvimento profissional com os saberes próprios do educador. Nesse sentido, García (1999, p. 22) traz à baila o conceito de formação de professores como o processo educativo profissionalizante para o ensino, proposto por Rodríguez Diéguez (1980). Apesar do sintagma profissionalizante remeter a uma ideia técnico-instrumental, no sentido de aquisição de competências para a atividade de ensino, é ponto pacífico que a docência exige mais que a presença de certas características ou qualidade. Portanto, García (1999) chama a atenção que, a 
centralidade da discussão do termo de Diéguez (1980) vem de entender que nas últimas décadas do século XX, no bojo do movimento da em prol da profissionalização, a luta contra a proletarização docente e a busca por autonomia vem em conjunto.

Com os estudos sobre a profissionalização docente, a figura do professor ficou cada vez mais central, em um processo educativo mais complexo, que demanda uma perspectiva de formação mais ampliada, crítica e reflexiva, diferentemente de uma visão instrumental, utilitária e fragmentada. Assim, o professor com sua formação deve ter uma postura de integração frente aos conteúdos e as realidades vividas, de forma a fomentar a autonomia, a construção de saberes entre os próprios docentes e, por conseguinte, entre os próprios alunos, como destaca Behrens (2003).

Com base em Ferry (1991), García (1999, p. 22) elenca o conceito de formação relacionado ao desenvolvimento individual com objetivo de aperfeiçoar características. Assim, para García (1999) a profissão docente se distingue da formação para as demais em três esferas: a primeira se refere que além de uma formação acadêmica específica, ela é acrescida de uma formação pedagógica, indicando assim uma duplicidade formativa. O segundo aspecto denota a necessidade de uma terceira formação, a profissional e por último, a formação de professores implica no desenvolvimento de formadores, o que demanda atenção aos conhecimentos e as práticas dos docentes. Portanto, a formação contém uma esfera pessoal que sofre impactos externos e sociais, bem como para que ela ocorra, é necessário vontade e capacidade, cabendo ao sujeito ativar, iniciar o seu processo de desenvolvimento formativo, sem implicar que a formação ocorra com o indivíduo sozinho ou de forma obrigatoriamente autônoma.

As histórias de vida, as experiências, as memórias e outros elementos que compõem as trajetórias dos sujeitos, também são formativos, já que congregam em espaços e tempos localizados, ações individuais e coletivas em prol de um trabalho e de contextos, interlocutores reais, concretos. Por isso, contribuições como Goodson (1992) e Nóvoa (1992) que trazem a relação explícita entre a formação e a vida dos professores, bem como as marcas no trabalho docente, reendossam outros elementos que impactam a formação. Portanto, destaca-se que o processo formativo pode ser entendido partindo do desejo próprio de se formar e da contribuição trocada com outros na constituição do eu formativo.

Na esteira de García (1999), Nóvoa (1992; 1995), Contreras (2002), entende-se a formação docente como um processo que prepara para a autonomia profissional e emancipação do pensamento, oportunizando aos professores refletirem de forma crítica sobre as práticas de ensino e aprendizagem, as realidades e os contextos que fazem parte, encaminhando para 
trabalhos coletivos, democráticos e participativos. Nesse sentido, emergiram perspectivas de pesquisas que enfocam na aprendizagem da docência, nos ciclos de vida e de carreira, bem e mal estar na docência, por exemplo, que congregam as marcas que os docentes trocam entre si, com os pares, com os interlocutores e com as relações de trabalho.

Assim, destaca-se a imagem do professor reflexivo, como um modelo preconizado para a formação, quer seja inicial ou continuada, postulando uma nova racionalidade para a profissão. Segundo Alarcão (2001), tal modelo visa em uma perspectiva futura, a longo prazo, formar professores que se baseiam em critérios coletivos e emancipatórios para a construção do conhecimento, que considerem todos os sujeitos produtores e produtos das realidades sociais, bem como que desenvolvam trabalhos reflexivos e em grupos.

Na mesma direção, Ghedin (2005) aponta que o projeto formativo de professores deve se guiar por um exercício de reflexão contínuo e organizado, visando que o docente se configure como um mediador, um facilitador para a construção de novos conhecimentos e metodologias para o ensino. E o autor ainda dispõe que a reflexão e a atitude reflexiva vão para além do desenvolvimento profissional e marcam uma postura de constituição do ser.

Os modos de se pensar e formar os indivíduos estão em constantes mudanças, em função das transformações mundiais nos níveis tecnológicos e de comunicação, com a cobrança por novas habilidades e competências. Nesse sentido, a formação assume um papel de contribuição para o acesso a cultura, ao trabalho e as tecnologias. Assim, Moraes (1997) aponta que perspectivas que concebiam o conhecimento de forma fragmentada vão paulatinamente perdendo o seu relevo, frente a paradigmas emergentes de conhecimento que postulam a construção de saberes de modo contextual, imbricada com os sujeitos e realizados de forma integrada, sistêmica e holística. Moraes (1997) ainda dispõe e, continua-se concordando, que a formação deve se pautar por diretrizes da fraternidade, da solidariedade, da cooperação que é trilhada a partir da construção coletiva dos saberes, dos entendimentos das demandas da sociedade, marcando portanto, o compromisso com a formação do cidadão que acredita e que participa do fazer científico.

Destarte, em meio a todos estes debates, um sentido que perpassa em muitas teorias é a da verve reflexiva da formação, alicerçada no entendimento do pensamento complexo, com descontinuidades, ampliado, aberto, referido aos contextos sociais e históricos, que persegue ao fim, uma integração entre os sujeitos, os espaços, os objetos, nos tempos de transformações e mudanças. 


\section{FORMAÇÃO INICIAL DE PROFESSORES E DE PROFESSORAS}

O desenvolvimento profissional atrela-se a formação, já que, uma das suas principais vias ocorre em sua via inicial, nos cursos de graduação, e continuada, a partir dos cursos de pós-graduação. Assim, García (2009) dispõe que o professor deva investir na construção de conhecimentos, via processos formativos, haja visto também que as transformações sociais e os sujeitos demandam novos saberes e posturas, continuamente da educação e dos professores.

Nesse sentido, a partir dos anos 1990 emergiu um paradigma de formação docente pensando no professor reflexivo e na interligação dos aspectos de pesquisa e ensino. Diferentemente do que se pautara anteriormente, guiado pela perspectiva da racionalidade técnica, que concebia o docente como um técnico a aplicar conhecimentos, executor de planejamentos e responsável pela transformação social dos menos favorecidos. Em termos legais, a Lei de Diretrizes e Bases (LDB), Lei $n^{\circ}$. 9.394/96, representou um passo para o reconhecimento da necessidade de revisão da formação de professores, gerando mudanças em currículos dos cursos de licenciatura e encaminhando para a valorização dos conhecimentos específicos da docência e em prol da profissionalização.

Em acordo com a LDB e para além dela, cabe ressaltar outros avanços legais no que se refere a formação iniciação de professores, como a Resolução $n^{\circ} 01$ de 2002 do Conselho Pleno (CP) do Conselho Nacional de Educação (CNE) que fixou as Diretrizes Curriculares Nacionais para a Formação de Professores da Educação Básica, em forma de graduação em licenciatura plena. Em 2015, o CNE lança a Resolução nº 02 que demarcou as Diretrizes Curriculares Nacionais para a formação de professores, refletindo sobre a formação pedagógica, cursos de licenciatura, realizados como primeiro e como segunda graduação e matrizes para a formação continuada. Os entendimentos atuais direcionam para ações que coadunem as diretrizes para a formação de professores com as diretrizes para a educação básica. Apesar de não ser o objeto do texto e nos furtando de aprofundamento, cabe mencionar que com as discussões recentes em relação a Base Nacional Comum Curricular (BNCC), a proposição de novos projetos para a formação de professores, currículos dos cursos de licenciaturas correlacionadas as disposições da BNCC.

O Parecer $n^{\circ}$. 01/2002 do CP/CNE em consonância com a LDB prescreve que a formação de professores deve privilegiar uma perspectiva da reflexão, das situações problemas para novos caminhos didáticos para o ensino. Assim, essa mesma visão é endossada no mesmo documento, que no terceiro artigo traz os seguintes princípios: 
Art. $3^{\circ} \mathrm{A}$ formação de professores que atuarão nas diferentes etapas e modalidades da educação básica observará princípios norteadores desse preparo para o exercício profissional específico, que considerem:

I - a competência como concepção nuclear na orientação do curso;

II - a coerência entre a formação oferecida e a prática esperada do futuro professor, tendo em vista:

a) a simetria invertida, onde o preparo do professor, por ocorrer em lugar similar àquele em que vai atuar, demanda consistência entre o que faz na formação e o que dele se espera;

b) a aprendizagem como processo de construção de conhecimentos, habilidades e valores em interação com a realidade e com os demais indivíduos, no qual são colocadas em uso capacidades pessoais;

c) os conteúdos, como meio e suporte para a constituição das competências;

d) a avaliação como parte integrante do processo de formação, que possibilita o diagnóstico de lacunas e a aferição dos resultados alcançados, consideradas as competências a serem constituídas e a identificação das mudanças de percurso eventualmente necessárias.

III - a pesquisa, com foco no processo de ensino e de aprendizagem, uma vez que ensinar requer, tanto dispor de conhecimentos e mobilizá- los para a ação, como compreender o processo de construção do conhecimento.

Bem como, a Resolução n ${ }^{\circ}$ 02/2015 do CP/CNE que a partir das disposições de formações inicial e continuada, seguem em um modelo reflexivo para os cursos e para os currículos das licenciaturas dos futuros profissionais da educação básica. Um outro exemplo que pode ser dado, é a Resolução n ${ }^{\circ}$ 01/2006 do CP/CNE que em específico ao curso de Pedagogia, traz as Diretrizes Curriculares, que vislumbrava em seu horizonte, a formação reflexiva de docentes.

A perspectiva de formação de professores em um víeis reflexivo, subverte os entendimentos de supervalorização de habilidades e competências aliadas a profissão docente, como uma das marcas das influências neoliberal e capitalista na educação. Entretanto, um dos polos responsáveis por essa mudança de paradigma na formação docente, são representados por associações e sindicatos trabalhistas e da sociedade civil, a exemplo da Associação Nacional de Pesquisa e Pós-Graduação em Educação (ANPEd) e da Associação Nacional pela Formação dos Profissionais da Educação (ANFOPE), que pautaram suas discussões em conhecimentos científicos chancelados e no compromisso social da docência e da educação com a formação de um país mais justo e menos desigual. Assim, nessa direção, o Parecer n ${ }^{\circ}$. 02/2015 do CP/CNE endossa e consolida o que fora retratado, a exemplo do trecho

I - a formação docente para todas as etapas e modalidades da educação básica como compromisso público de Estado, buscando assegurar o direito das crianças, jovens e adultos à educação de qualidade, construída em bases científicas e técnicas sólidas em consonância com as Diretrizes Curriculares Nacionais para a Educação Básica; II - a formação dos profissionais do magistério (formadores e estudantes) como compromisso com projeto social, político e ético que contribua para a consolidação 
de uma nação soberana, democrática, justa, inclusiva e que promova a emancipação dos indivíduos e grupos sociais, atenta ao reconhecimento e à valorização da diversidade e, portanto, contrária a toda forma de discriminação;

III - a colaboração constante entre os entes federados na consecução dos objetivos da Política Nacional de Formação de Profissionais do Magistério da Educação Básica, articulada entre o Ministério da Educação (MEC), as instituições formadoras e os sistemas e redes de ensino e suas instituições;

IV - a garantia de padrão de qualidade dos cursos de formação de docentes ofertados pelas instituições formadoras;

V - a articulação entre a teoria e a prática no processo de formação docente, fundada no domínio dos conhecimentos científicos e didáticos, contemplando a indissociabilidade entre ensino, pesquisa e extensão;

VII - um projeto formativo nas instituições de educação sob uma sólida base teórica e interdisciplinar que reflita a especificidade da formação docente, assegurando organicidade ao trabalho das diferentes unidades que concorrem para essa formação; VIII - a equidade no acesso à formação inicial e continuada, contribuindo para a redução das desigualdades sociais, regionais e locais;

IX - a articulação entre formação inicial e formação continuada, bem como entre os diferentes níveis e modalidades de educação;

X - a compreensão da formação continuada como componente essencial da profissionalização inspirado nos diferentes saberes e na experiência docente, integrando-a ao cotidiano da instituição educativa, bem como ao projeto pedagógico da instituição de educação básica;

XI - a compreensão dos profissionais do magistério como agentes formativos de cultura e da necessidade de seu acesso permanente às informações, vivência e atualização culturais.

Ghedin (2005) denota que as mudanças nos paradigmas de formação docente são relacionados com a quebra de visões que preconizavam o trabalho como uma aplicação de técnicas e que não entendiam os professores enquanto sujeitos. Portanto, uma das principais mudanças se refere ao professor assumir uma posição de protagonismo no processo formativo, como um sujeito histórico, alicerçado no compromisso social da profissão e da educação. Assim, Pimenta e Lima (2004) destacam que conceitos como competências e habilidades, comumente utilizados em contextos neoliberais, saem de cena e/ou perdem a centralidade nas dinâmicas de formação de professores.

Os novos paradigmas norteadores da formação docente preconizam a figura do professor reflexivo e pesquisador, acompanhando tendências de estudos mundiais, encaminhando para a direção que os docentes são sujeitos ativos, um dos protagonistas dos processos educativos e com capacidade de articulação entre atividades de pesquisa e de ensino, bem como de refletirem sobre suas práticas. Pimenta (2002) destaca que essas novas abordagens são relevantes para a formação docente por considerarem o processo de construção de saberes e de conhecimentos, bem como de integrarem a pesquisa ao ensino. Nessa mesma linha, Azevedo (2008), concordando com Pimenta (2002), retrata que a atividade de reflexão está intimamente ligada a da pesquisa, aproximando ainda mais o professor reflexivo do pesquisador e fomentando uma tônica para os cursos de formação. 
García (1999) discorre que para se pensar a formação do professor pesquisador deve-se também refletir sobre as questões relacionadas ao desenvolvimento organizacional do estabelecimento escolar, na direção que os dilemas e os desafios ocorridos ou envolvendo a instituição, sejam também espaços e instrumentos de aprendizagem para os professores. Logo, o autor considera que a formação precisa ser encarada como uma atividade que tenha duas dimensões, a individual e a coletiva.

Ramalho, Nuñez e Gauthier (2004) pensando a formação de professores através do paradigma emergente, que Moraes (1997) compreende como sistêmico, ampliado e global, que preconiza as relações entre os sujeitos, diferentemente da forma fragmentada que concebia o anterior, os autores imaginam o professor como

\footnotetext{
Sujeito ativo e autônomo de sua prática. Nessa perspectiva, os professores constroem seus saberes, competências e sua identidade profissional num processo complexo, a partir de suas experiências, necessidades, interesses balizados pelo contexto institucional no qual desenvolve seu trabalho.
}

Seguindo a mesma linha de raciocínio dos outros autores citados, Ramalho, Nuñez e Gauthier (2004) apontam também que a formação deve se firmar em um sólido ramo teóricoprático, que compreenda as implicações históricas, de trabalho e de cultura que são envolvidas, fazendo emergir questionamentos sobre os modos de se ensinar e de aprender que estão na ordem do dia entre os desafios para os docentes. Imbernón (2006) refletindo acerca desses debates, entende que a formação e o seu fim têm como objetivo

\footnotetext{
Dotar o professor de conhecimentos, habilidades e atitudes para desenvolver profissionais reflexivos ou investigadores. Nessa linha, o eixo fundamental do currículo de formação dos professores é o desenvolvimento da capacidade de refletir sobre a própria prática docente com o objetivo de aprender a interpretar, compreender e refletir sobre a realidade social da docência. (IMBERNÓN, 2006, p. 39).
}

Conforme apontamentos de Imbernón, a formação precisa ser pensada de forma holística, valorizando um caráter analítico, reflexivo sobre as práticas educativas, fomentando a construção de conhecimentos relacionados aos contextos sociais e as idiossincrasias dos sujeitos, marcando diametralmente diferenças com as concepções tecnicistas sobre a formação e o ser professor. Imbernón (2006) ainda dispõe que, em relação aos saberes da profissão, que o professor deva ter uma gama vasta e consolidada de conhecimentos variados, para que possa atuar na complexidade, em contextos de mudanças, que não são exclusivos da escola, não 
obstante, de toda sociedade. Portanto, a figura de professor preconizada não se relaciona com as ideias voluntarista ou assistencialista, mas sim, de um profissional que partir das vivências e experiências de suas práticas cotidianas, reconhece as desigualdades, as injustiças, a divulgação de ideologias nocivas ao coletivo e a exploração. Na esteira do exposto, o autor afirma que "não se trata de aprender um ofício no qual predominam estereótipos técnicos, e sim de aprender os fundamentos da profissão, porque se realizam determinadas ações, adotam-se algumas atitudes concretas, quando e por que será necessário fazê-lo de outro modo" (IMBERNÓN, 2006, p. $65)$.

Acerca dos princípios e das ações da profissão docente, os debates têm apontado que eles não podem ser pensados de forma separada do espaço educativo, já que a formação inicial deve ser potencializada ao máximo para os futuros professores. Nesse sentido, Gatti (2010) discorre que a formação de professores parte do reconhecimento da função social da escolarização, das práticas didáticas e educativas e da responsabilidade frente aos interlocutores, crianças e adolescentes, muitas das vezes. Portanto, os futuros professores já trazem conhecimentos e experiências sobre os processos educativos e sobre o que é ser professor, enquanto alunos, e no momento da formação inicial, eles podem reconhecer, confrontar e estruturar suas concepções. Assim, Gatti (2010) propõe que a formação precisa estar relacionada aos espaços formativos, uma vez que eles são propulsores dos conhecimentos da profissão e que ocupam uma dimensão social na vida dos sujeitos.

\section{CONSIDERAÇÕES FINAIS}

O presente artigo se debruçou em realizar uma análise teórica acerca do campo de estudos da formação de professores, principalmente no que se refere ao conceito de formação e ao seu estágio inicial. Assim, em um primeiro momento, localizamos os movimentos formativos a partir da vida do ser humano e suas origens etimológicas e de sentidos, relacionando-as a educação e as práticas educativas. Em seguida, o artigo iniciou uma discussão teórica específica acerca da categoria formação e suas apropriações no campo educacional, mobilizadas principalmente por García (1999), que condensa os estudos pertinentes ao termo. No avançar dos debates, a reflexão sobre as práticas educativas e os modelos de formação discutidos ganha espaço, no sentido de pensar em como a formação mobiliza e reverbera as atividades de ensino-aprendizagem. 
Destarte, o texto focou na dimensão da formação inicial, discutindo as políticas e regimentos legais que a alicerçam, refletindo os cursos universitários de licenciatura. E as perspectivas que encaminhavam de forma geral para as práticas educativas, agora são mais localizadas, refletindo o compromisso social e político da educação e da profissão docente, com a transformação e com o ensino de qualidade e relacional com os interlocutores.

\section{REFERÊNCIAS}

ALARCÃO, I. (Org.). Escola reflexiva e nova racionalidade. Porto Alegre: Artmed Editora, 2001.

AZEVEDO, R. O. M. Ensino de ciências e formação de professores: diagnóstico, análise e proposta. Manaus: Universidade do Estado do Amazonas, 2008.

BEHRENS, M. A. O paradigma emergente e a prática pedagógica. 3.ed. Curitiba:

Champagnat, 2003.

BRASIL Ministério da Educação e do Desporto. Lei n. 9.394/96 - Lei de Diretrizes e Bases da Educação Nacional. Brasília, 2001. Disponível em: http://www.planalto.gov.br/ccivil_03/Leis/L9394.htm>

BRASIL. Resolução CNE/CP 1, de 18 de fevereiro de 2002. Institui Diretrizes Curriculares Nacionais para a Formação de Professores da Educação Básica, em nível superior, Curso de Licenciatura, de graduação plena. Brasília, 2002. Disponível em: <http://portal.mec.gov.br/cne/arquivos/pdf/rcp01_02.pdf>.

BRASIL. Parecer n. 9/2001, de 08 de maio de 2001. Diretrizes Curriculares Nacionais para a Formação de Professores da Educação Básica, em nível Superior, curso de licenciatura, de graduação Plena. Conselho Nacional de Educação. Disponível em: $\langle$ http://portal.mec.gov.br/cne/arquivos/pdf/009.pdf>.

BRASIL. RESOLUÇÃO CNE/CP N ${ }^{\circ}$, DE 15 DE MAIO DE 2006. Institui Diretrizes Curriculares Nacionais para o Curso de Graduação em Pedagogia, licenciatura. Disponível em: <http://portal.mec.gov.br/cne/arquivos/pdf/rcp01_06.pdf >.

BRASIL. RESOLUÇÃO CNE/CP $\mathrm{N}^{\circ} 2$, de 01 de julho de 2015. Define as Diretrizes Curriculares Nacionais para a formação inicial e continuada dos profissionais do magistério da educação básica. Disponível em: <http://portal.mec.gov.br/index. php?option=com_docman \&view $=$ download\&alias $=17625$-parecer-cne-cp-2-2015-aprovado9-junho-2015\&category_slug=junho-2015-pdf\&Itemid=30192.pdf $>$.

CHARLOT, B. Da relação com o saber: elementos para uma teoria. Tradução Bruno Magne. Porto Alegre: Artes Médicas Sul, 2000.

CONTRERAS, J. A autonomia de professores. São Paulo: Cortez, 2002.

DEBESSE, M. Um problema clave de la educación escolar contemporânea. In: DEBESSE, M.; MIALARETY, G. (Ed.). La formación de los enseñantes. Barcelona: Oikos-Tau, 1982, p. 1334.

FERRY, G. El trayecto de la formación. Los enseñantes entre la teoría y la práctica. Barcelona: Paidós, 1991. 
FULLAT, O. Filosofias da educação. Petrópolis: Vozes, 1994.

GATTI, B. A. Formação de professores no Brasil: características e problemas. Educ. Soc., Campinas, v. 31, n. 113, p. 1355-1379, out-dez. 2010.

GARCÍA, C. M. Formação de professores: para uma mudança educativa. Portugal: Porto Editora, 1999.

GARCÍA, C. M. Desenvolvimento profissional docente; passado e futuro. Revista Sísifo. Revista de Ciências da Educação, v. 08, FPCE: UL, jan/abr, 2009, p. 07-22.

GHEDIN, E. Professor reflexivo: da alienação da técnica à autonomia da crítica. In: PIMENTA, S.; GHEDIN, E. Professor reflexivo no Brasil: gênese e crítica de um conceito. São Paulo: Cortez, 2005. p. 129-150.

GOODSON, I. F. Dar voz ao professor: as histórias de vida dos professores e o seu desenvolvimento profissional. In: NÓVOA, A. (Org.). Vidas de professores. Porto: Porto Editora, 1992. p. 63-78.

IMBERNÓN, F. Formação docente e profissional: formar-se para a mudança e a incerteza. São Paulo: Cortez, 2006.

LIBÂNEO, J. C. Didática. São Paulo: Cortez, 1994.

MENZE, C. Formación. In: SPEAK J. et al (Org.). Conceptos Fundamentales de Pedagogía. Barcelona: Herder, p. 267-297, 1980.

MORAES, M. C. O paradigma educacional emergente. Campinas: Papirus, 1997.

NÓVOA, A. Os professores e a sua formação. Lisboa: Dom Quixote, 1992.

NÓVOA, A. (Coord.). Os professores e sua formação. Lisboa: Dom Quixote, 1995.

PERISSÉ, G. Filosofia da educação. Belo Horizonte: Autêntica, 2008.

PIMENTA, S. G. (Org.). Saberes pedagógicos e atividade docente. São Paulo: Cortez, 2002, p.15-38.

PIMENTA, S. G.; LIMA, M. S. L. Estágio e docência. São Paulo: Cortez, 2004.

RAMALHO, B. L.; NUÑEZ, I. B.; GAUTHIER, C. Formar o professor, profissionalizar o ensino: perspectivas e desafios. Porto Alegre: Sulina, 2004.

VIEIRA PINTO, A. Ciência e existência. Rio de Janeiro: Civilização Brasileira, 1969.//

ZABALZA, M. A. O estágio e as práticas em contextos profissionais na formação universitária. São Paulo: Cortez, 2014. 